\title{
Pushing the Envelope of Pedagogical Gaming: Dark Networks
}

Michael E. Freeman, Naval Postgraduate School

ABSTRACT In recent decades, instructors have increasingly adopted the use of "serious" games in their classrooms. Typically, these games take the form of role-playing simulations or wargames. However, online computer-run games have opened up new possibilities: to explore complex conceptual relationships, to utilize and display asymmetric information, to be playable anywhere and by anyone, and more. This article describes the game, Dark Networks, and shows why this type of game is valuable as well as how it has been used for pedagogical gains.

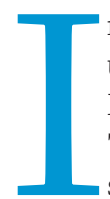
$\mathrm{n}$ recent decades, instructors have increasingly adopted the use of "serious" games in their classrooms (Asal 2005, 6; McCarthy 2014, 401; Shellman and Turan 2006, 19). Typically, these games take the form of role-playing simulations or wargames (Bridge and Radford 2014, 423; Filter n.d.). However, online computer-run games have opened up new possibilities: to explore complex conceptual relationships, to utilize and display asymmetric information, to be playable anywhere and by anyone, and more (Jackson 2013, 210, 212; Starkey and Blake 2001, 540-1; Weir and Baranowski 2011, 442).

As the principal investigator on a Department of Defensesponsored project, I oversaw the development of 12 online games, mostly focused on issues of terrorism and insurgency. In the most recent academic year, 30 courses used-and about 1,500 students played-these games.

In this article, I first situate our style of games in comparison to other types of games. I then describe one game in particular, Dark Networks. Finally, I address why this game is useful and how the game has been implemented. Much of the how and why of Dark Networks follows the conventional wisdom of best practices in the literature on gaming-but with added benefits from being an online computer-based game.

\section{THE UNIVERSE OF GAMES}

Games can take numerous forms, but of particular interest are the types of games that have demonstrable pedagogical value in the classroom, which often are called serious games. Strategic games are those that pit players against one another in an interactive

Michael E. Freeman is associate professor in defense analysis at the Naval Postgraduate School. He can be reached at mefreema@nps.edu. The views expressed in this article are those of the author and do not reflect the official policy or position of the Department of Defense or the US Government. and contingent environment, in which the success of one player's strategy depends on how it interacts with the opponent's strategy. Some of the earliest strategy games include Go, Petteia, Latrunculi, Chaturanga, and Chess (Lewin 2012, chaps. 1, 2; Perla 1990), which then added more realism with, for example, the Avalon Hill-style games in the twentieth century. In a different vein, in role-playing simulations, players assume a specific role and negotiate/interact/ coordinate with other players in a seminar-style environment. Typically, these games are focused on real-life scenarios and are adjucicated by a human control team, and they may be aided by computer communication tools (Lane 1995, 605-7; McCarthy 2014, 405). Wargaming (a particular style of role-playing simulation) was undertaken by militaries to understand, anticipate, and plan for war beginning with the creation of Kriegsspiel in 1824 (Lewin 2012, 40-52; Perla 1990, 35-42) and likely reached its peak in the mid-twentieth century, when large tabletop (or even larger) wargaming exercises were used by numerous militaries including the Japanese, British, and Americans in World War II (Hanley 1991, ch. 4; Perla 1990, 51-68; Perla and McGrady 2011, 111).

Within this universe, the games we developed can be thought of as strategic, multiplayer games about war (but not wargames), computer adjudicated, and available online. Importantly, our games try to model a simplified version of conceptual rather than empirical reality (Jackson 2013, 211). Most of our games revolve around choosing actions (i.e., policies) and dealing with the consequences of those actions, all while the player's opponent is doing the same. Many of the games incorporate elements of asymmetry-of information, movement, power, and so on.

\section{DARK NETWORKS}

The Dark Networks game focuses on the organizational structure of terrorist groups and how these structures can be altered to make these "dark networks" more or less effective (Milward and Raab 2006; 
Raab and Milward 2003). It reinforces many of the concepts and ideas from the field of social network analysis (SNA) (Borgatti, Everett, and Johnson 2013; Scott 2013; Wasserman and Faust 1994). It is a two-player strategic game between the state and the terrorist. Both the state and the terrorist players are taking actions that affect a randomly generated (within certain parameters) terrorist network of nodes and the links between them. (For a discussion of the value of using "fictional" cases, see Asal and Blake 2006, 7.) The terrorist network is further divided into three subnetworks: financial, logistical, and operational.

The core tradeoff in this game is between security and effectiveness for the terrorist group. Measures taken to increase effectiveness the actions of previous turns during the course of the game; once the game is over, they can "playback" the game and see all actions from both sides (Asal and Blake 2006, 6). Since its development and deployment online, Dark Networks has been incorporated into 17 iterations of courses at various institutions in two previous academic years. Short descriptions of all 12 games, including Dark Networks, are available at www.globalecco.org.

\section{WHY}

Why should an instructor, class, curriculum, or student use a game like Dark Networks? The three most important answers are (1) pedagogy, (2) social interaction and team building, and (3) fun.

\section{Most of our games revolve around choosing actions (i.e., policies) and dealing with the conse- quences of those actions, all while the player's opponent is doing the same. Many of the games incorporate elements of asymmetry-of information, movement, power, and so on.}

will diminish the terrorist group's security and vice versa. This forces players to think about which attribute (i.e., security or effectiveness) they want to maximize at different times in the game.

Victory is based on the overall terror level, which is determined by the size and number of attacks that the terrorist player can execute. However, the precise impact of any attack on the terror level depends on the organizational structure of the terrorist group. The terrorist player can take several types of action to change the structure of the network and/or the activities in which it engages. It can grow or shrink, centralize or decentralize, increase its popular support, and build external ties to gather resources that are necessary to conduct attacks. Stated simply, if the terrorist group is bigger, more centralized, and has more popular support and more external ties that bring in resources, then its attacks will have a greater effect. It is important, however, that becoming bigger, more centralized, and so on also makes the terrorist group less secure and more vulnerable to disruptive actions by the state. Figure 1 is a screenshot of the terrorist view of the game.

Whereas the terrorist player sees the entirety of the terrorist network, the state player sees only a few nodes to begin the game. The state can gather intelligence to learn more about the network and reveal more nodes and links. The state also can deny resources to the terrorist, kill or capture specific nodes, deny the terrorist's popular support, and increase its security presence to mitigate the effects of terrorist attacks. Figure 2 is a screenshot of the state view of the game.

Both players simultaneously take three actions per turn. This forces players to make difficult strategic choices about what to prioritize.

This game could not exist as anything but a computer game. The foremost reason is that the networks are randomly created for each game, and each node has an underlying "detectability" value that goes up or down depending on the state's intelligence actions, efforts at decentralization, and so on. These are recalculated for each node on each turn based on the action undertaken by both players (Starkey and Blake 2001, 541), all with asymmetric information about the network visualized for both players. Also, numerous actions affect variables; calculating these interdependent effects would be prohibitively complicated if it were not a computer game. Furthermore, the game allows for players to show
(Note that other styles of games have other uses, such as training and analysis, but they are not discussed here.)

\section{Pedagogy}

The most important argument for games is that they help students learn in the classroom (Lane 1995, 610; Murphy et al. 2015, 165; Rivera and Simons 2008, 299; Ruben 1999). Although there continues to be skepticism about the pedagogical effectiveness of games (Raymond 2010; 2014; Raymond and Usherwood 2013), scholars increasingly have found evidence that they are effective (D’Angelo et al. 2014; Kahn and Perez 2009, 333-4; Krain and Lantis 2006; McCarthy 2014; Rubel 2006, 112; Shapiro 2014; Shellman and Turan 2006; Silvia 2010). Students who play games are actively engaged in the delivery of the learning material as opposed to passively listening or watching in a classroom (Archer and Miller 2011; Bromley 2013, 818; Dewey 1938; Rivera and Simons 2008; Silvia 2010). Students must think through both their own actions and their opponent's responses to them during game play; this "metacognitive" activity enhances learning (Fadel and Lemke 2008, 12). Games also engage students by tapping into the cognitive and emotional appeal of "participatory narrative experiences" (Arnold 2015, 162; Perla and McGrady 2011, 113).

In every course using Dark Networks, we have seen similar evidence. For example, students might conceptually understand the value (or not) of targeting a key node in a network; however, when they choose to make that decision in the game, they quickly engage with all of the complicating factors. Which node? On which turn should they do it? How much information do they need to feel comfortable with their decision? How will the terrorist player react? How do they convince their teammates that it is the right choice? Should they kill or capture the node? Which other policy choices are they willing to forego in order to take their desired action? This active decision making does not occur if students are merely absorbing a lecture or discussing a concept. Second, most students/players buy into the narrative of the game, playing as the roles would suggest, and-most important-are emotionally engaged because they want to win. Several course instructors noted that some students had been completely silent and seemingly disengaged from the course yet became active participants with their teammates once the game was underway. 
Games can be used to reinforce the core concepts of a course (Bridge 2013, 814). For Dark Networks, the game reinforces the notions of network centralization (how centralized or decentralized the network is) (Cunningham, Everton, and Murphy 2016, ch. 4), as well as node centrality (how connected a specific node is within the network) (Cunningham et al. 2016, ch. 6); how the network's size changes its effectiveness in perpetrating violence (Cunninhgam et al. 2016, ch. 4); external and internal ties and the optimizing their own goals and strategies. In past iterations of a course that teaches SNA, the instructor (and subject-matter adviser for the game development) had students develop a network map of a terrorist group and then present their strategy to counter the network. Undoubtedly, it was useful for thinking about opening strategies, but it did not consider how the opponent would immediately respond and adapt, and neither did it consider how this interaction would progress over time. This instructor currently

\section{Students must think through both their own actions and their opponent's responses to them during game play; this "metacognitive" activity enhances learning (Fadel and Lemke 20o8, 12).}

value of each type (Krackhardt and Stern 1988, 127); why "dark" networks need at least some popular support (Roberts and Everton 2011, 5-6); how the state must make decisions with incomplete information about terrorist networks (Cunningham et al. 2016, 31); that the state can attack the network (through kill or capture operations) but also can/must invest in defensive measures that mitigate the effects of terrorist attacks; and that both sides must make difficult choices about which policies to prioritize and which to not pursue.

Games often are particularly useful for helping students learn to think strategically-that is, how to identify realistic goals and the best means to achieve them-while facing opponents who are uses Dark Networks as a strategic "lab" at the end of the course (Asal and Blake 2006, 2). Because both players take actions simultaneously each turn for 15 turns, players assess how their strategic choices interact with their opponent's actions. The state player cannot simply say "let's attack this key node" without thinking about how the terrorist player would respond.

Games also can be used to encourage strategic experimentation and "outside-the-box" thinking (Asal 2005, 362; Lane 1995, 613; Perla 1990, 170; Rubel 2006, 114; Wedig 2010, 548). Most people play games to win, but games also can be used to test new strategies without any real-world consequences. Moroever, games can "close the time gap between strategy implementation and

\section{Figure 1}

\section{Terrorist View}

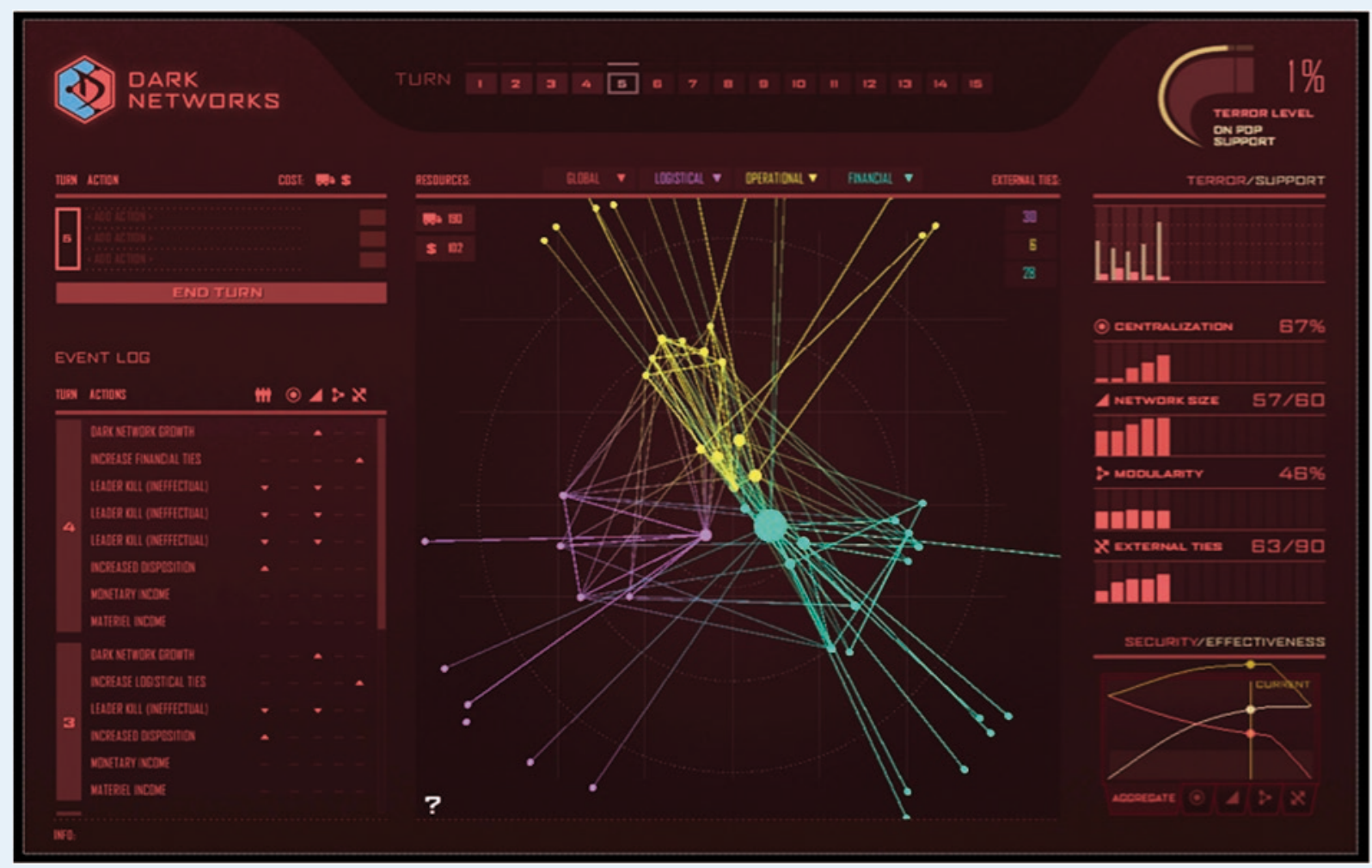


outcome" while focusing only on the key variables (Lane 1995, 613), which allows the game to strike the right balance between realism/complexity and playability (Asal and Blake 2006, 8). In Dark Networks, players can experiment with different strategies (Cunningham et al. 2016, 22-32; Roberts and Everton 2011). We have observed state players use an information-focused strategy for developing a more robust intelligence picture of the network before deciding to target nodes (and lose when they attacked the network "too soon"); try a leadership-targeting strategy of undermining the network by targeting key nodes (and lose when the nodes were only relatively important in hoping it can survive the state's efforts to dismantle it; and develop a hybrid approach of constant but low-level attacks.

\section{Social Value}

Games, particularly two-player or multiplayer versions or those in which students are put on teams, give students the opportunity to interact with their classmates. This can be a valuable icebreaking exercise (Balleck and Van Tassell 2004, 353), such as at the beginning of a short course, and also a team-building tool (Rubel 2006, 113). For example, a short course on border security used one of our games to get the

\section{In nearly every course that utilized one of our games, the games are recognized in post-course reviews as a highlight. Students often ask to continue playing the games instead of moving on to other course material.}

a decentralized network); take a kinetic "whack-a-mole" approach of killing every node discovered (often to poor results); focus on undermining the terrorist group's popular support through information operations; and deny the terrorist network access to the prerequisite resources needed to conduct attacks. Likewise, we have observed terrorist players try to immediately "go big" with constant attacks; patiently build their network and resources, participants, who were international representatives from various ministries (e.g., Interior, Defense, and Justice) to talk with one another in ways that they would not normally do in their daily job routine. Games are a natural activity to enhance the formation of collaborative teams that compete against one another, thereby stimulating classroom discussion, social interactions, and friendly competition (Asal 2005, 362).

\section{Figure 2}

State View

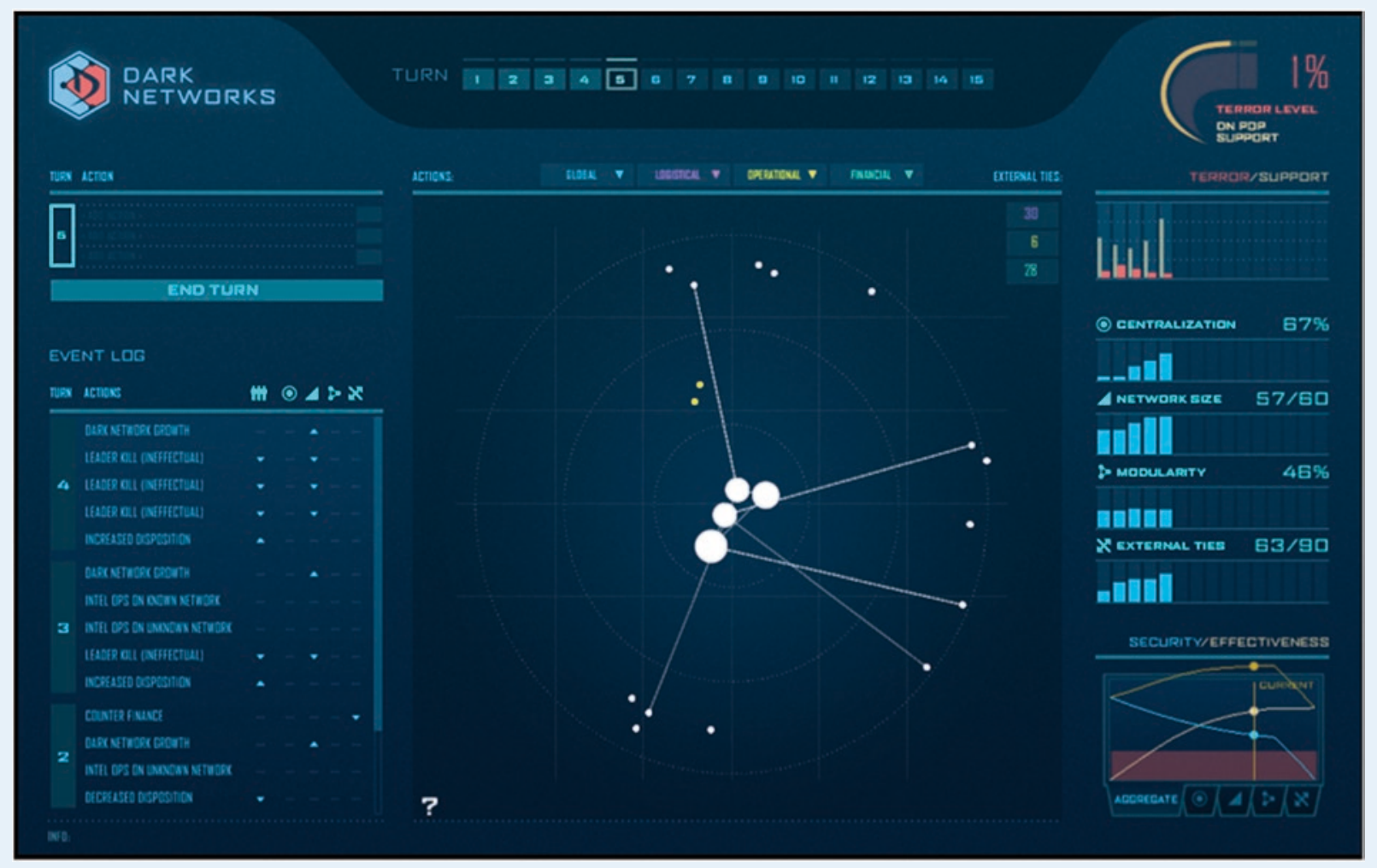




\section{Fun}

Games also provide a welcome change of pace from standard classroom work, especially lectures. Active-learning techniques (Archer and Miller 2011; Bromley 2013), of which gaming is only one type, have been shown to be effective because they break up the monotony of the classroom, refreshs students' minds, and help them become reengaged with the course material. In nearly every course that utilized one of our games, the games are recognized in post-course reviews as a highlight. Students often ask to continue playing the games instead of moving on to other course material.

Ultimately, games-even serious games-should be fun. Although this objective is secondary to the more important pedagogical goals of serious gaming, the more students enjoy the process of learning, the more quickly they will become engaged and the longer they will stay engaged-with not only the course material but also the broader curriculum (Murphy et al. 2015, 33-8).

\section{HOW}

Games are not for every student or every course (Asal 2005, 361-2). The idea of using games to study serious topics may spark resistance from instructors and students alike (Carvalho 2014). Instructors must decide whether using games makes sense for a particular course and, if so, how best to use the games that they choose (MacDonald et al. 2015, 273; Raymond and Usherwood 2013, 162; Wedig 2010, 548).

When planning to introduce a game into a course, the first question the instructor should ask is, "What is the purpose of the game?" Is it to teach a specific point, reinforce broad concepts, challenge students to think strategically, or something else (Asal 2005, 361)? More specifically, the instructor must clearly understand whether and how the game achieves this purpose better than or differently from other materials (Rivera and Simons 2008, 300-301).

How much class time should be devoted to the game is always a concern (Balleck and Van Tassell 2004, 351; Jackson 2013, 210). A game that takes five or even 30 minutes to play is easier to incorporate than one that takes several hours or longer. For Dark Networks, two hours or less is usually sufficient to play at least two games, one as the state and one as the terrorist. Playing both sides is especially valuable for students to appreciate the unique complexities of each side (Baranowski and Weir 2010, 217). After students have become familiar with Dark Networks, a typical game might last 10 to 15 minutes.

When to play the game also is an important consideration. Icebreaker games usually are played early in a course, as are games meant to set the stage for later discussions (Arnold 2015; McCarthy 2014, 402; Siegel and Young 2009, 765), whereas capstone-type exercises typically are played at the end. Games meant to reinforce a particular subject or concept can be played at any time during the course.

Instructors should think carefully about what they need to do before, during, and after the game is played (Asal 2005, 362-5; Wedig 2010). Before a game is played, the instructor must become familiar with the game, fully grasp its pedagogical purpose, and share that purpose with students (Asal and Blake 2006, 4; Kanner 2007, 795). While the game is being played, the instructor should use the game-play and students' questions to reinforce themes, concepts, or debates from class (Asal 2005, 363; Wedig 2010, 552). Ideally, to learn the rules and "buttonology," students could play a short throwaway version of the game before playing it "for real." In some courses, as a brief demonstration of the interface and rules before students play on their own, the instructor displays both sides of Dark Networks and has them walk through their choices for a few turns.

To obtain the most value from the exercise, after a game is played, it is essential that the instructor allows time to ask students what they learned from the game and how it reinforced course themes and material (Asal 2005, 364; Kahn and Perez 2009, 334; Wedig 2010, 553) because "games are not self-teaching" (Raymond and Usherwood 2013, 163). It also is important to allow students to share lessons that the instructor might not have anticipated. In using Dark Networks, we have seen students note that they were surprised at the importance of the terrorist's popular support, that targeting key nodes is effective only in centralized organizations, and that the state should at least gather some intelligence on the network before taking actions. All of these, and more, are valuable teaching points that were not fully appreciated until the game was played.

\section{USING SERIOUS GAMES: CONCLUSION}

By designing online games like Dark Networks and facilitating their use across multiple institutions, we have seen firsthand how they engage students with the course and with one another and how they can be used to enhance the instruction of course material. Moreover, as a web-based computer game, Dark Networks shows how technology can simulate complex and abstract concepts, calculate interdependent variables, and model interactions so that players can experiment with strategic decisions in ways they otherwise would not.

Ultimately, serious games can be excellent tools to enhance strategic courses and the learning of students who take them. Games entice students to think, engage, interact, and learn in ways that other teaching methods cannot provide. However, games are not beneficial for every class or every instructor. Instructors must fully understand the benefits, uses, and limitations of serious games if they are to use them to their best advantage.

\section{REFERENCES}

Archer, Candace, and Melissa Miller. 2011. "Prioritizing Active Learning: An Exploration of Gateway Courses in Political Science." PS: Political Science \& Politics 44 (2): 429-34.

Arnold, Richard. 2015. "Where's the Diplomacy in Diplomacy? Using a Classic Board Game in 'Introduction to International Relations'." PS: Political Science \& Politics 48 (1): 162-6.

Asal, Victor. 2005. "Playing Games with International Relations." International Studies Perspectives 6 (3): 359-73.

Asal, Victor, and Elizabeth Blake. 2006. "Creating Simulations for Political Science Education." Journal of Political Science Education 2 (1): 1-18.

Balleck, Barry, and Darin Van Tassell. 2004. "Making the World More Relevant for Students: Role-Playing Exercise for the Classroom." Politics and Policy 32 (2): 345-81.

Baranowski, Michael, and Kimberly Weir. 2010. "Power and Politics in the Classroom: The Effect of Student Roles in Simulations." Journal of Political Science Education 6 (3): 217-26.

Borgatti, Stephen P., Martin G. Everett, and Jeffrey C. Johnson. 2013. Analyzing Social Networks. Thousand Oaks, CA: Sage Publications.

Bridge, Dave. 2013. "The Settlement Game: A Simulation Teaching Institutional Theories of Public Law." PS: Political Science \& Politics 46 (4): 813-17.

Bridge, Dave, and Simon Radford. 2014. "Teaching Diplomacy by Other Means: Using an Outside-of-Class Simulation to Teach International Relations Theory." International Studies Perspectives 15 (4): 423-37.

Bromley, Pam. 2013. "Active Learning Strategies for Diverse Learning Styles: Simulations Are Only One Method." PS: Political Science \& Politics 46 (4): 818-22. 
Carvalho, Gustavo. 2014. "Virtual Worlds Can Be Dangerous: Using Ready-Made Computer Simulations for Teaching International Relations." International Studies Perspectives 15 (4): 538-57.

Cunningham, Daniel, Sean F. Everton, and Philip J. Murphy. 2016. Understanding Dark Networks: A Strategic Framework for the Use of Social Network Analysis. Lanham, MD: Rowman and Littlefield.

Curry, John. 2013. The British Kriegsspiel. History of Wargaming Project.

D’Angelo, Cynthia, Daisy Rutstein, Christopher Harris, Robert Bernard, Evgueni Borokhovski, and Geneva Haertel. 2014. Simulations for STEM Learning: Systematic Review and Meta-Analysis (Executive Summary). Menlo Park, CA: SRI International.

Dewey, John. 1938. Experience and Education. New York: Collier Books.

Fadel, Charles, and Cheryl Lemke. 2008. "Multimodal Learning Through Media: What the Research Says." Available at www.cisco.com/web/strategy/docs/ education/Multimodal-Learning-Through-Media.pdf.

Filter, John. N.d. "Gaming Political Science” website. Available at www.k-state.edu/ polsci/gaming.

Hanley, John. 1991. On Wargaming: A Critique of Strategic Operational Wargaming. New Haven, CT: Yale University, PhD Dissertation.

Jackson, Steven. 2013. "Political Simulations Using Excel." Journal of Political Science Education 9 (2): 209-21.

Kahn, Melvin, and Kathleen Perez. 2009. "The Game of Politics Simulation." Journal of Political Science Education 5 (4): 332-49.

Kanner, Michael. 2007. "War and Peace: Simulating Security Decision Making in the Classroom." PS: Politics \& Political Science 40 (4): 795-99.

Krackhardt, David, and Robert Stern. 1988. "Informal Networks and Organizational Crises: An Experimental Simulation." Social Psychology Quarterly 51 (2): 123-40.

Krain, Matthew, and Jeffrey Lantis. 2006. "Building Knowledge? Evaluating the Effectiveness of the Global Problems Summit Simulation." International Studies Perspectives 7 (4): 395-407.

Lane, David. 1995. "On a Resurgence of Management Simulations and Games." Journal of the Operational Research Society 46 (5): 604-25.

Lewin, Christopher George. 2012. War Games and Their History. Havertown, PA: Fonthill Media.

MacDonald, Jo, Perry McDowell, Daniel Siegel, and Jesus R. De Leon. 2015. "Integrating Games into Learning Environments." In Design and Development of Training Games, ed. Talib Hissain and Susan Coleman, 273-302. New York: Cambridge University Press.

McCarthy, Mary. 2014. "The Role of Games and Simulations to Teach Abstract Concepts of Anarchy, Cooperation, and Conflict in World Politics." Journal of Political Science Education 10 (4): 400-13.

Milward, H. Brinton, and Jörg Raab. 20o6. "Dark Networks as Organizational Problems: Elements of a Theory." International Public Management Journal 9 (3): 333-6o.

Murphy, Curtiss, Dustin Chertoff, Michael Guerrero, and Kerry Moffitt. 2015. "Design Better Games: Flow, Motivation, and Fun."In Design and Development of Training Games, ed. Talib Hissain and Susan Coleman, 146-78. New York: Cambridge University Press.

Perla, Peter. 1990. Art of Wargaming. United States Naval Institute Press. (Page numbers in citations refer to the 2011 edition edited by Curry 2013.)

Perla, Peter, and Ed McGrady. 2011. "Why Wargaming Works." Naval War College Review 64 (3): 111-30.

Raab, Jörg, and H. Brinton Milward. 2003. "Dark Networks as Problems.” Journal of Public Administration Research and Theory 13 (4): 413-39.

Raymond, Chad. 2010. "Do Role-Playing Simulations Generate Measurable and Meaningful Outcomes? A Simulation's Effect on Exam Scores and Teaching Evaluations." International Studies Perspectives 11 (1): 51-60.

_. 2014. "Can't Get No (Dis) Satisfaction: The Statecraft Simulation's Effect on Student Decidion Making." Journal of Political Science Education 10 (3): 302-14.

Raymond, Chad, and Simon Usherwood. 2013. "Assessments in Simulations." Journal of Political Science Education 9 (2): 157-67.

Rivera, Sharon Werning, and Janet Thomas Simons. 2008. "Engaging Students Through Extended Simulations." Journal of Political Science Education 4 (3): 298-316.

Roberts, Nancy, and Sean F. Everton. 2011. "Strategies for Combating Dark Networks." Journal of Social Structure 12 (2).

Rubel, Robert. 2006. “The Epistomolgy of War Gaming." Naval War College Review 59 (2): 108-28.

Ruben, Brent. 1999. "Simulations, Games, and Experience-Based Learning: The Quest for a New Paradigm for Teaching and Learning." Simulation and Gaming 30 (4): 498-505.

Scott, John. 2013. Social Network Analysis. London and Thousand Oaks, CA: Sage Publications.

Shapiro, Jordan. 2014. "Games in the Classroom: What the Research Says." KQED Mind/Shift. Available at https://ww2.kqed.org/mindshift/2014/06/27/games-inthe-classroom-what-the-research-says.

Shellman, Stephen, and Kürşad Turan. 2006. "Do Simulations Enhance Student Learning? An Empirical Evaluation of an IR Simulation." Journal of Political Science Education 2 (1): 19-32.

Siegel, David, and Joseph Young. 2009. "Simulating Terrorism: Credible Commitment, Costly Signaling, and Strategic Behavior." PS: Political Science and Politics 42 (4): 755-71.

Silvia, Chris. 2010. "The Impact of Simulations on Higher Level Learning." Paper presented at the American Political Science Association Annual Meeting. Washington, DC: September 2-5.

Starkey, Brigid, and Elizabeth Blake. 2001. "Simulation in International Relations Education." Simulation and Gaming 32 (4): 537-51.

Wasserman, Stanley, and Katherine Faust. 1994. Social Network Analysis: Methods and Applications. Cambridge, UK: Cambridge University Press.

Wedig, Timothy. 2010. "Getting the Most from Classroom Simulations: Strategies for Maximizing Learning Outcomes.” PS: Politics \& Political Science 43 (3): 547-55.

Weir, Kimberly, and Michael Baranowski. 2011. "Simulating History to Understand International Politics.” Simulation and Gaming 42 (4): 441-61. 